\title{
Protein kinase C-delta regulates HIV-1 replication at an early post-entry step in macrophages
}

\author{
Xavier Contreras ${ }^{1,4,5^{*}}$, Olfa Mzoughi ${ }^{1,2,3}$, Fabrice Gaston ${ }^{1,2,3}$, Matija B Peterlin ${ }^{4}$ and Elmostafa Bahraoui ${ }^{1,2,3^{*}}$
}

\begin{abstract}
Background: Macrophages, which are CD4 and CCR5 positive, can sustain HIV-1 replication for long periods of time. Thus, these cells play critical roles in the transmission, dissemination and persistence of viral infection. Of note, current antiviral therapies do not target macrophages efficiently. Previously, it was demonstrated that interactions between CCR5 and gp120 stimulate PKC. However, the PKC isozymes involved were not identified.

Results: In this study, we identified PKC-delta as a major cellular cofactor for HIV-1 replication in macrophages. Indeed, PKC-delta was stimulated following the interaction between the virus and its target cell. Moreover, inhibition of PKC-delta blocked the replication of R5-tropic viruses in primary human macrophages. However, this inhibition did not have significant effects on receptor and co-receptor expression or fusion. Additionally, it did not affect the formation of the early reverse transcription product containing R/U5 sequences, but did inhibit the synthesis of subsequent cDNAs. Importantly, the inhibition of PKC-delta altered the redistribution of actin, a cellular cofactor whose requirement for the completion of reverse transcription was previously established. It also prevented the association of the reverse transcription complex with the cytoskeleton.
\end{abstract}

Conclusion: This work highlights the importance of PKC-delta during early steps of the replicative cycle of HIV-1 in human macrophages.

\section{Background}

Cells of the monocyte/macrophage lineage play a central role in HIV-1 infection and pathogenesis. In addition, macrophages play important roles for viral transmission and dissemination $[1,2]$. Indeed, the primary infection is initiated and carried out by macrophage-tropic viruses, which use, in addition to CD4, the CCR5 co-receptor. Macrophages are also one of the main reservoirs of HIV-1. This latter property is related to the lack of viral cytopathic effects in macrophages which ensures their survival when compared to infected CD4 positive lymphocytes [3-5]. Furthermore, current therapies that target HIV-1 replication are not as efficient in macrophages as they are in lymphocytes [6]. As a consequence, macrophages, in contrast to $\mathrm{CD} 4$ positive $\mathrm{T}$ cells, are not depleted during the course of HIV-1 infection. Thus, a better understanding of HIV-1 replication and the

\footnotetext{
* Correspondence: contreras.xavier@gmail.com; bahraoui@cict.fr

'Université Paul Sabatier, EA 3038, 118 Route de Narbonne, Toulouse 31062 France

2INSERM, U1043, CPTP, CHU purpan, BP3028, Toulouse, Cedex3 31024, France Full list of author information is available at the end of the article
}

finding of efficient therapies for macrophages remain major challenges.

In addition to using CCR5 as the co-receptor for entry into its cellular targets, HIV-1 hijacks the underlying cellular machinery. Interactions between the viral gp120 envelope glycoprotein, CD4 receptor, and CCR5 co-receptor trigger a signaling cascade, which is comparable to that observed with their natural ligands. Initiated through the G-alpha proteins, these signals mobilize intracellular free calcium, translocate PKC, activate Pyk2, FAK. Erk1/2, Rho GTPases, and decrease levels of intracellular cAMP [7-12]. By facilitating the first steps of HIV-1 entry and trafficking in target cells, they play essential roles in the viral replicative cycle [9,13-19].

Among these pathways, PKC plays a critical role. In cells, where HIV-1 replicates efficiently, PKC must be activated. PKC isozymes (probably alpha and beta), which are activated by interactions between CCR 5 and HIV-1, play a major role in the rearrangement of the actin cytoskeleton that is required for viral entry [9]. In addition to facilitating entry, via the phosphorylation of I $\mathrm{KB}$ (Inhibitor of NF$\kappa B)$, PKC stimulates Nuclear Factor $\kappa B(N F-\kappa B)$ [20-22].

\section{Biomed Central}


$\mathrm{NF}-\mathrm{kB}$ binds to the HIV-1 promoter and increases its transcription [23]. PKC also activates AP-1 and NF-AT $[24,25]$ which also bind to the HIV-1 promoter. Moreover, PKC can phosphorylate a number of viral proteins such as p17Gag [26], Nef [27-29] and Rev [30], although the functional role(s) for their phosphorylation is poorly understood.

Eleven PKC isozymes have been described [31,32]. They have been classified depending mainly on their mechanism of action. They differ also in their subcellular localization and substrate specificity. Different types of cells express distinct PKC isozymes. Since PKC is triggered via CCR5, it is critical to determine which PKC isozymes are stimulated and their roles in the HIV-1 replicative cycle.

Of these, PKC-delta plays a central role in the differentiation of monocytes, which resist HIV-1 infection [33,34], to macrophages, which are permissive for infection $[35,36]$. Indeed, macrophage differentiation induced by monocyte colony stimulating factor (M-CSF) $[37,38]$ or by PMA [39] depends on PKC-delta, which also activates $\mathrm{NF}-\mathrm{kB}[38,40]$ and associates with vimentin in the cytoskeleton [41]. Additionally, the C2 domain of PKC-delta contains an actin-binding site. This binding could be involved in the redistribution of actin in neutrophils $[42,43]$. Thus, PKC-delta is a very attractive cellular cofactor for HIV-1 infection, particularly in macrophages. However, the expression of PKC-delta is not restricted to macrophages. Thus, effects of PKC-delta, which are addressed by this study, could be extrapolated to other cell types such as $\mathrm{T}$ lymphocytes, where the cytoskeleton also plays a critical role in the viral replicative cycle.

In this study, we characterized effects of PKC-delta on HIV-1 replication in human macrophages and demonstrated that it plays a critical role at an early step of infection.

\section{Results \\ PKC-delta plays a major role in HIV-1 BaL replication in macrophages}

To determine the role of PKC in viral replication, macrophages were infected with the R5-tropic HIV-1 BaL in the presence or absence of chemical inhibitors of PKC. HIV-1 replication was assessed at day 3 post-infection using p24 ELISA (Figure 1A). Ro31-8220 (5 $\mu \mathrm{M})$, which inhibits all PKC isozymes, decreased greatly (94\%) viral replication (Figure 1A, lane 2). Interestingly, rottlerin $(5 \mu \mathrm{M})$, a specific PKC-delta inhibitor [44], also blocked viral replication, whereas hispidin, a PKC-beta inhibitor, had little to no effect (Figure 1A, lanes 3 to 6). In addition, Go6976, which inhibits PKC-alpha, beta and gamma, had limited effects on viral replication (Figure 1A, lanes 7 and 8). These results suggest that $\mathrm{PKC}$-delta plays an important role in HIV-1 infection of macrophages. Moreover, as

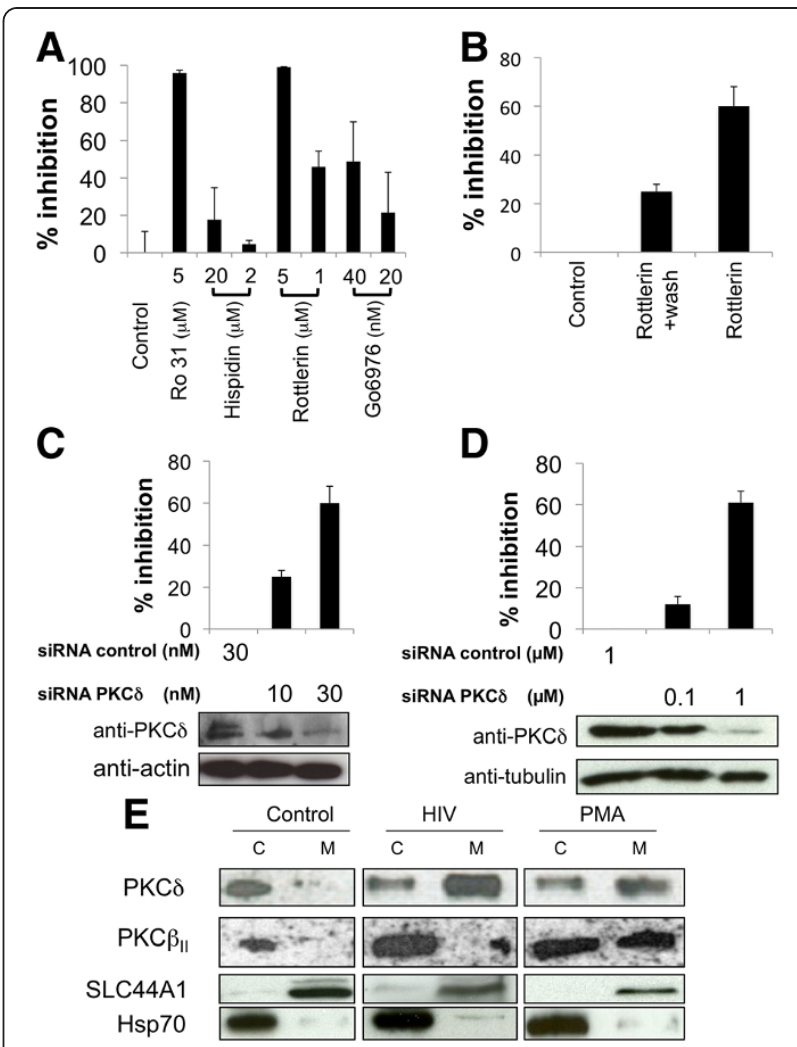

Figure 1 PKC-delta is required for HIV-1 BaL replication in human macrophages. (A) Macrophages $\left(5 \times 10^{5}\right)$ were pretreated for 30 min with Ro31-8220, an inhibitor of all PKCs, or by selective inhibitors of certain PKC isozymes (rottlerin, PKC-delta inhibitor, Hispidin PKC-beta inhibitor and Gö6976, PKC-alpha, beta, and mu inhibitor) at indicated concentrations. HIV-1 BaL infection (1 ng p24/ml) lasted $3 \mathrm{~h}$. After 3 days culture supernatants were collected and viral replication assessed by the presence of p24 determined by ELISA. (B) $5 \times 10^{5}$ macrophages were preincubated with rottlerin for $24 \mathrm{~h}$ and then cultured in rottlerin free medium for $24 \mathrm{~h}$ before infection to evaluate cytotoxic effects of rottlerin (rottlerin + wash). As positive control, the total inhibitory effect of rottlerin was evaluated as described in panel A. Error bars represent 3 experiments with one donor. Results are representative of experiments achieved in three different donors. (C) HeLa LTR-beta-gal cells or (D) macrophages were preincubated with siRNA against PKC-delta or scrambled siRNA for 2 days. Cells were then infected with HIV-1 BaL (1 ng p24) for $3 \mathrm{~h}$ and washed. After $48 \mathrm{~h}$, cells were treated with $\mathrm{X}$-gal and infection was assessed by counting betagal positive blue cells using microscopy (C) or by quantifying p24 in the supernatant (D). Western blot with anti PKC-delta antibodies is shown as the control. (E) Macrophages $\left(5 \times 10^{6}\right)$ were infected with HIV$1 \mathrm{BaL}(1 \mathrm{ng}$ p24/ml) or stimulated by PMA for 30 minutes, and the activation of PKC isozymes was determined by analyzing PKC translocation to the membrane. Membrane bound (M) and cytoplasmic (C) proteins were extracted and separated by 10\% SDS-PAGE. PKC-delta and beta| isozymes were visualized by chemiluminescence using specific antibodies for each isozyme. Homogeneity of protein extracts was controlled by amido black staining of membranes. The purity of membrane and cytoplasmic fractions was controlled by Western blotting for SLC44A1 (membrane) and Hsp70 (cytoplasm). Results are representative of three independent experiments. 
assessed by trypan blue exclusion, rottlerin was not cytotoxic at these concentrations (Additional file 1: Figure $\mathrm{S} 1 \mathrm{~A})$; and HIV-1 BaL replication was similar in macrophages pre-treated or not with rottlerin $(5 \mu \mathrm{M})$ for $24 \mathrm{~h}$, and subsequently washed and cultured for an additional $24 \mathrm{~h}$ (Figure $1 \mathrm{~B}$ and data not shown). Thus the effect of rottlerin is reversible. Strikingly, the preincubation of HeLa-CD4-CCR5-CXCR4 (HeLa-R5/X4) cells with increasing concentrations of siRNA [45] or antisense oligonucleotides targeting PKC-delta [46] inhibited viral replication by 62 and $85 \%$, respectively, while control siRNA or sense oligonucleotides had little to no effect (Figure $1 \mathrm{C}$ and Additional file 1: Figure S1B). Indeed at these conditions, PKC-delta expression was suppressed strongly by siRNA or antisense oligonucleotides (Figure 1C, lower panels and Additional file 1: Figure S1C). Replication of X4-tropic viral strain HIV-1 VN44 was also inhibited in HeLa-R5/X4 pre-incubated with siRNA against PKC-delta (Additional file 2: Figure S2). To further confirm the effects of the PKC-delta knockdown on viral replication, we infected primary human macrophages pre-incubated with siRNAs against PKC-delta with HIV-1 BaL. We observed a $60 \%$ inhibition of viral replication at conditions in which PKC-delta expression was reduced by siRNA (Figure 1D, lane 2). This inhibition was in agreement with decreased levels of PKC-delta (Figures 1C and 1D, lower panels). Altogether, these results demonstrate the importance of PKC-delta in the HIV-1 replicative cycle in macrophages.

Since PKC-delta plays an important role in viral replication, next, we sought to determine whether interactions between HIV-1 BaL and the target cell activate this isozyme. In unstimulated cells, PKC isoforms are localized to the cytoplasm. However, following their activation, they undergo conformational changes and translocate to the membrane. Taking this finding into account, we followed the activation of PKC-delta by its presence in cytoplasmic and membrane fractions in macrophages, which were preincubated with or without HIV-1 BaL. Figure 1E demonstrates that following 30 min incubation with HIV-1 BaL (1 ng p24), PKC-delta translocated to the membrane fraction of macrophages (Figure 1E, compare lanes 2 and 4). This activation was even stronger than that by PMA, a phorbol ester, which is widely used for the activation of PKC (Figure 1E, lanes 5 and 6). In contrast, in unstimulated cells, PKC-delta was present only in the cytoplasm (Figure 1E, compare lanes 1 and 2). On the contrary, PKC-beta ${ }_{\text {II }}$ did not translocate to the membrane after the incubation with viral particles, but only after macrophages were stimulation by PMA (Figure 1E, lanes 5 and 6). Taken together these results demonstrate a critical role for PKC-delta in viral replication. They also indicate that interactions between viral particles and target macrophages lead to its activation.

\section{Inhibition of PKC-delta restricts HIV-1 replication at a post-entry step}

To determine the role(s) of PKC-delta on viral entry, we first measured the expression of cell surface markers required for interactions between HIV-1 and macrophages, i.e. CD4 and CCR5, by flow cytometry (Figure 2A). Preincubation of macrophages with rottlerin $(5 \mu \mathrm{M})$ had

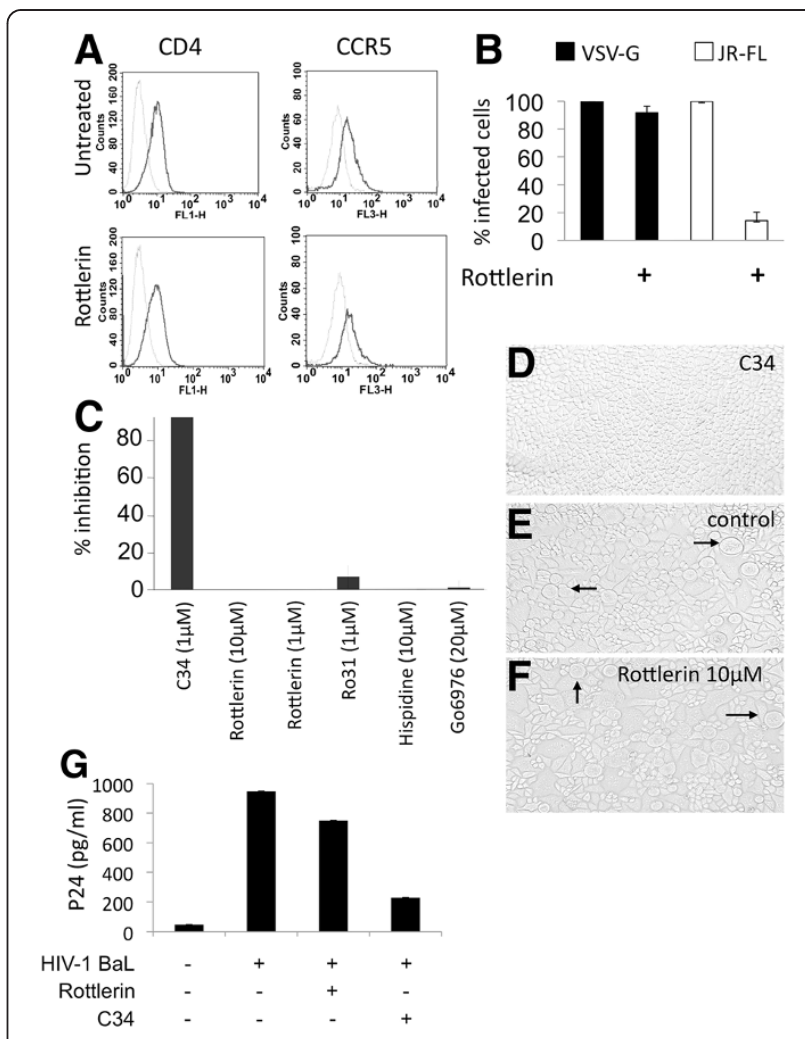

Figure 2 Effects of rottlerin on viral entry. Macrophages $\left(5 \times 10^{5} / \mathrm{ml}\right)$ were untreated or treated with rottlerin $(5 \mu \mathrm{M})(\mathbf{A})$ for 30 minutes or (B) 2hours. (A) Cells were then stained for CD4 or CCR5 and analyzed by FACS. Dashed lines correspond to unstained cells, solid lines to specific staining. (B) Cells were then transduced with equal $\mathrm{MOI}$ of VSV-G- or JR-FL-pseudotyped vectors carrying a GFP reporter plasmid. Two days later, GFP-positive cells were counted using microscopy. Results are represented as relative levels of infection, with infected control cells set to $100 \%$. Error bars are from triplicates of a single experiment. Results are representative of 3 independent experiments. (C) Cell fusion was measured by syncytia formation in a co-culture of cells expressing CD4 and CCR5 or gp120 and gp41, in the presence or absence of PKC inhibitors rottlerin, hispidin, Ro318220, Co6976, or the fusion inhibitor C34 as the control. (D), (E) and (F) Phase contrast microscopy images of syncytia in a coculture of cells expressing either CD4 and CCR5 or gp120 and gp41, in the presence of C34 (D), rotllerin $10 \mu \mathrm{M}(\mathbf{F})$ or without inhibitors (E). Arrows indicate syncytium formation. (G) Macrophages were pretreated or not with rottlerin or C34 fusion inhibitor for 30 minutes and infected with HIV-1 BaL for $3 \mathrm{~h}$, washed and treated with trypsin. After extensive washing, cells were lysed and p24 quantified using p24 ELISA. 
no significant effect on the expression of CD4 and CCR5. This result suggests that $\mathrm{PKC}$-delta does not affect the expression of HIV-1 receptor or co-receptor. Next, macrophages were transduced in the presence or absence of rottlerin with lentiviral vectors coding for GFP (Green Fluorescent Protein) and pseudotyped with the envelope glycoprotein of the M-tropic HIV-1 JR-FL or the VSV-G protein. In addition to its wide tropism, the $G$ protein of VSV mediates virus entry by endocytosis in a $\mathrm{pH}$ dependent manner. This situation is unlike that with the HIV-1 envelope glycoprotein, which mediates virus entry via a $\mathrm{pH}$-independent mechanism. Cells transduced by these vectors were analyzed for the expression of the GFP gene. Figure $2 \mathrm{~B}$ demonstrates that macrophages were transduced successfully by both vectors. When these experiments were performed in the presence of rottlerin $(5 \mu \mathrm{M})$ (Figure $2 \mathrm{~B})$, the number of GFP-positive cells was similar to that found with VSV-G pseudotyped vectors in the absence of this inhibitor. In contrast, when examined under the same conditions, this number was strongly reduced for HIV-1 JR-FL pseudotyped vectors (90\% inhibition). Thus, the inhibition of PKC-delta has a strong effect on HIV-1 JR-FL, but not VSV-G pseudotyped viral particles. These results demonstrate that the mode of entry determines the requirement for PKC-delta. Indeed, both vectors have similar mechanism by which their RNA is reverse transcribed, integrated and expressed, but differ in their mechanism of entry. Previous studies suggested already that, after entry via endocytosis, the viral genome in the reverse transcription complex is released in close proximity to the nucleus and thus does not require migration across regions of the cell such as the actin cortical mesh [47]. Thus, both the mode of entry and early postentry steps are different in HIV-1 JR-FL and VSV-G pseudotyped lentiviral vectors. To discriminate between these two possibilities, we examined the formation of syncytia between HeLa-R5/X4 and HeLa-gp120/gp41, which express the envelope from the R5 tropic HIV-1 ADA. Under these conditions, rottlerin and other PKC inhibitors did not block the fusion of membranes (Figures 2C-F). To determine effects of PKC-delta inhibition on viral entry, we also pretreated macrophages first with rottlerin and then incubated them with HIV-1BaL for additional 3 hours at $37^{\circ} \mathrm{C}$. To remove adsorbed viruses, cells were treated with trypsin. We used levels of intracellular p24 (measured by ELISA) as a marker of virus entry. Indeed, similar levels of p24 were found in cells treated or not with rottlerin (Figure 2G). As a control, to ensure that levels of p24 correspond to intracellular antigen and not to adsorbed viruses after trypsin digestion, we used a known inhibitor of fusion, the C34 peptide [48]. In its presence, the virus continues to bind to its receptors, but it becomes unable to induce membrane fusion. As expected, levels of p24 dropped strongly in the presence of the C34 peptide, confirming the specificity of this assay (Figure 2G). Taken together, these results indicate that blocking PKC-delta does
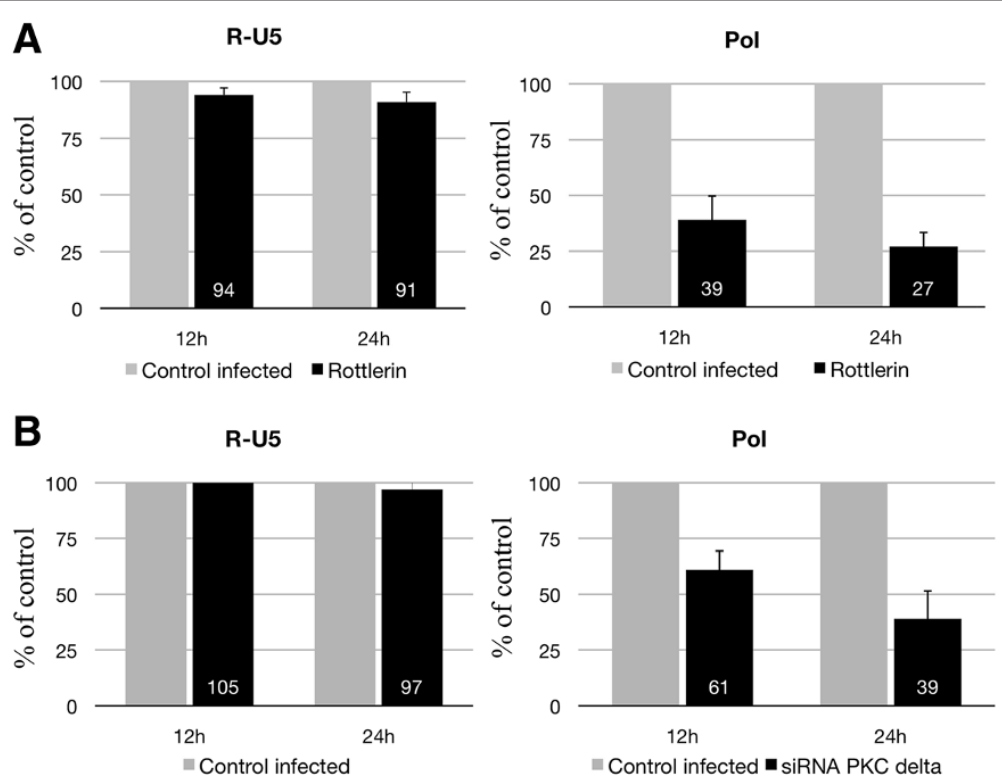

Figure 3 Quantitative PCR of RT products (cDNA) from HIV-1 BaL-infected macrophages pretreated or not with rottlerin or accel siRNA against PKC-delta. Macrophages $\left(5 \times 10^{5}\right.$ cells/well) were pretreated by rottlerin $(5 \mu \mathrm{M})$ for 30 minutes $(\mathbf{A})$ or with accel siRNAs against PKC-delta for 3 days (B) and then infected with HIV-1 BaL (1 ng p24) for $3 \mathrm{~h}$ at $37^{\circ} \mathrm{C}$ and washed. Cells were then lysed at $12 \mathrm{~h}$ and $24 \mathrm{~h}$ after infection, and DNA was analyzed by PCR. Amplification of the early (R-U5) and late (pol) products of RT was performed by quantitative PCR (qPCR). Three independent experiments with macrophages from three different donors gave similar results. 
not interfere with virus entry and further suggest that this inhibition occurs at an early step in the viral replicative cycle.

\section{Inhibition of PKC-delta affects an early step of reverse transcription}

To determine effects of inhibiting PKC-delta on transcription, HeLa-R5/X4 cells, which contain an integrated LTR-beta-galactosidase reporter gene, were incubated in presence of GST-Tat (Additional file 3: Figure S3). The addition of rottlerin had only small effects on GST-Tatinduced transactivation of the HIV-1 LTR. Similarly, transduction of macrophages with VSV-G pseudotyped lentiviral vectors encoding GFP under the control of HIV-1 LTR led to equivalent levels of GFP expression in the presence or absence of this inhibitor (Figure 2B). These results suggest that inhibiting PKC-delta does not affect HIV-1 transcription and gene expression.

Next, we analyzed early steps that follow the entry of HIV-1 into macrophages. To this end, we pretreated macrophages with rottlerin or siRNA against PKC delta and harvested viral DNA at different times after the infection (12 and 24 h). DNA was extracted and quantitative PCR analyses were conducted with oligonucleotides specific for early (R-U5) and late (pol) reverse transcription (RT) products (Figure 3). Early RT products were detected with all conditions (Figure 3 ). These results indicate that this early step of RT is not blocked following PKC-delta inhibition by rottlerin or knock-down by siRNA. In contrast, PCR amplification of late (pol) RT products was attenuated greatly after rottlerin treatment (Figure 3A). We observed a $61 \%$ and $73 \%$ inhibition at $12 \mathrm{~h}$ and $24 \mathrm{~h}$, respectively. Late RT products were also reduced in siRNA-treated cells (Figure 3B). These results suggest that inhibiting PKC-delta inhibits the synthesis of late RT products in macrophages. Overall, these results suggest that PKC-delta is required at the level of early reverse transcription, soon after the initiation of viral cDNA synthesis.

\section{Inhibition of PKC-delta impairs the integrity of actin cytoskeleton in human macrophages}

Since interaction between the RT complex and actin cytoskeleton is necessary for the elongation of reverse transcriptase [47], next we analyzed effects of rottlerin on the organization of actin cytoskeleton. Macrophages were preincubated with or without rottlerin for $24 \mathrm{~h}$, and labeled with phalloidin, a specific ligand of F-actin (the monomer forming actin microfilaments), which was coupled to rhodamine, a fluorescent probe. Cells were then observed using confocal microscopy. As a control, untreated macrophages contained a number of pseudopods, which are projections of the cytoplasm towards the exterior of the cell that result from cytoskeletal rearrangements of actin (Figure 4A-B). In these untreated macrophages, actin microfilaments organize in stress fibers (Figure 4A, see arrow). However, in rottlerin-pretreated macrophages, very few pseudopods (Figures $4 \mathrm{C}$ ) were observed, and they did not contain stress fibers (Figure 4C). Interestingly, this effect was reversible. Thus, in cells that were preincubated with rottlerin and then cultured without the inhibitor, we observed the restoration of normal cytoskeleton (Figure 4E lane 3). Importantly, siRNA against PKC-delta had similar effects on the actin cytoskeleton as rottlerin, although to a lesser extent (Figures 4D and $4 \mathrm{E}$, lane 6). In addition, inhibitors of other PKC isozymes such as hispidin or go6976 had no major effects on actin filaments (Figure 4E). Thus, these data indicate that inhibiting PKC-delta affects the integrity of the actin cytoskeleton in macrophages.

Since the reverse-transcriptase complex from the incoming virus interacts with actin microfilaments [49], we hypothesized that inhibiting PKC-delta could lead to its dissociation from the actin cytoskeleton. To address this question, we fractionated cellular and cytoskeletal

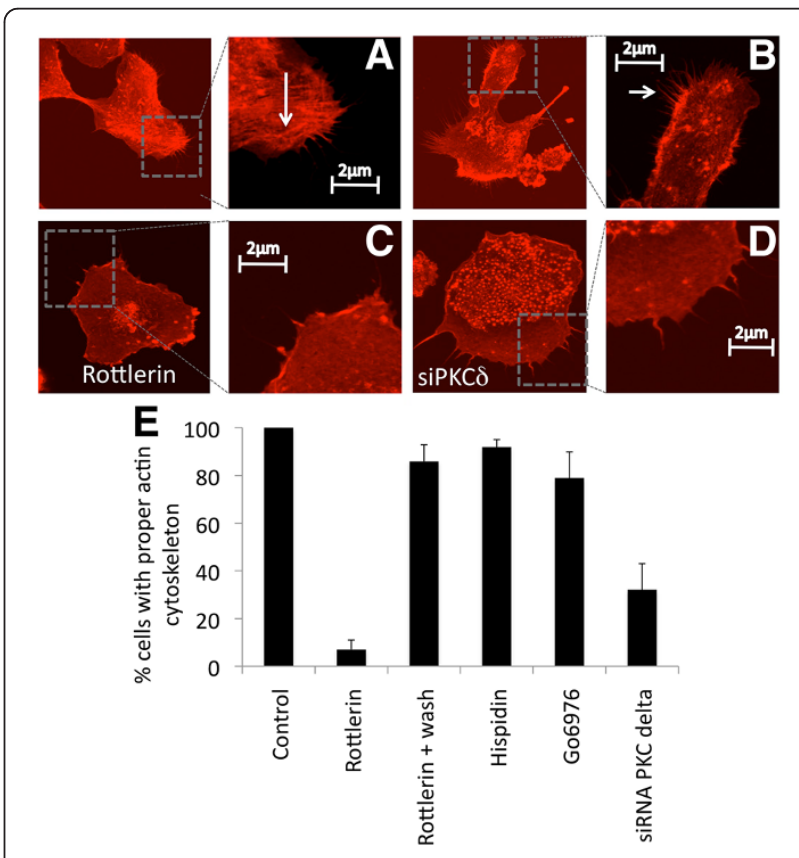

Figure 4 Actin cytoskeleton is altered by pretreatment of macrophages by rottlerin $(5 \mu \mathrm{M})$. Human macrophages were treated for $24 \mathrm{~h}$ with rottlerin $(5 \mu \mathrm{M}, \mathbf{C})$, transfected with siRNAs to PKC-delta (D) or left untreated (A and B) and then fixed with formaldehyde (3.7\%). Macrophages were then permeabilised with Triton X-100 (0.2\%) and stained with rhodamine-phalloidin before mounting using moviol. Preparations were then observed by confocal microscopy. Confocal images are representative of three independent experiments. Arrows indicate stress fibers $(\mathbf{A})$ and pseudopods (B). (E) Quantitative results represent the percentage of cells with proper actin cytoskeleton in the presence of different inhibitors or after treatment with siRNA against PKC-delta. 
proteins from macrophages, which were pretreated or not with rottlerin and then infected with HIV-1 BaL. RT (Figure 5A) or matrix proteins (Gag-MA) (Figure 5B) were detected by Western blotting. In cells infected with HIV- or VSV-G-pseudotyped lentiviral vectors, RT was found in the membrane and cytoskeletal fractions (Figure 5A). However, RT was not found in the cytoskeletal fraction following the pre-treatment with rottlerin. Similar results were obtained using the Gag-MA as a marker (Figure 5B). Additionally, using cytochalasin D (CCD) as a control to disrupt actin polymerization, the Gag-MA was also not found in the cytoskeletal fraction. Taken together, these results suggest that PKC-delta is required for cytoskeletal integrity, which is essential for early steps in viral replication.

\section{Discussion}

It was previously shown that $\mathrm{PKC}$ can be stimulated via interaction between CCR5 and gp120 [9]. This activation facilitates HIV-1 replication at different steps of its replicative cycle including entry, integration and gene expression $[9,44,50,51]$. However, these studies did not investigate thoroughly the role of different PKC isozymes in macrophages. For this reason, we investigated the involvement of PKCdelta, which plays an important role in the differentiation of macrophages, in HIV-1 replication. Our work was performed using complementary approaches including the chemical inhibitor rottlerin, specific antisense oligonucleotides, and specific siRNA. We demonstrated for the first time that HIV-1 is able to activate PKC-delta in macrophages. Importantly, we demonstrated that PKC-delta is critical for the replication of HIV-1 in human macrophages.
Several steps of the viral replicative cycle were analyzed to identify the one that was affected by this inhibition. Our results indicate that there is no block to viral entry upon inhibiting PKC-delta. Indeed, the expression of viral receptor (CD4) and co-receptor (CCR5) was not altered. Nevertheless, a recent study demonstrated that inhibiting PKC-alpha and/or beta could reduce the expression of these surface molecules in CD4 T lymphocytes [9]. It is thus possible that different PKC isozymes serve different functions in different cellular contexts. Further supporting our data, in the presence of PKC inhibitors, fusion occurred normally as assessed by syncytia formation in cocultures with HeLa cells expressing R5/X4 and gp120/ gp41 from HIV-1 Lai or HIV-1 ADA. This latter finding was confirmed by quantifying levels of intracellular p24 after incubating macrophages with HIV-1 ADA in the presence or absence of PKC inhibitors. All these studies, including levels of receptor/co-receptor and membrane fusion, suggest that the step of entry was not affected by inhibiting PKC-delta.

We also demonstrated that later steps, such as transcription, were not affected as demonstrated by the ability of Tat to activate the HIV-1 LTR similarly in the presence or absence of PKC inhibitors. This lack of effect of PKC-delta inhibitors on transcription was also confirmed with the expression of LTR-GFP from cells treated with rottlerin and transduced with VSV-G-pseudotyped vectors. Indeed, the transduction of macrophages with VSV-G-pseudotyped, but not with HIV-1 JR-FL lentiviral vectors, was insensitive to PKC-delta inhibition. VSV-G pseudotyped vectors use an alternative pathway for RTC (RT complexes) delivery to the cytosol and thus bypass HIV-
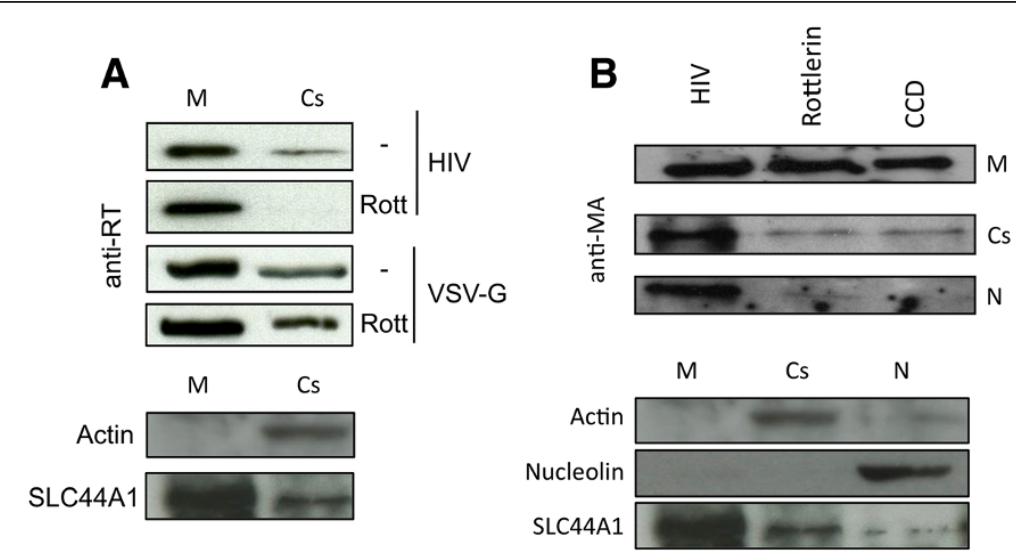

Figure 5 Rottlerin reduces cytoskeletal association of HIV-1 RT complexes. (A) Macrophages $\left(5 \times 10^{6}\right)$ were left untreated or pretreated with rottlerin (Rott) and then infected with HIV-1 BaL (50 ng p24) or VSV-G-pseudotyped vector (10 ng p24). Membrane bound (M) and cytoskeletal (Cs) fractions were obtained and the presence of HIV-1 RT was assessed by Western blotting (upper panels). Purity of membrane bound and cytoskeletal fractions was analyzed by Western blotting for control proteins (bottom panels). (B) Macrophages $\left(5 \times 10^{6}\right)$ were left untreated or pretreated with rottlerin or cytochalasin D (CCD) and then infected with HIV-1 BaL (50 ng p24). Membrane bound (M), cytoskeletal (Cs) and nuclear ( $N$ ) fractions were obtained, and the presence of Gag-MA was assessed by Western blotting (upper panels). The purity of membrane bound, cytoskeletal and nuclear fractions was analyzed by Western blotting for control proteins (bottom panels). 
mediated early entry steps. This difference of sensitivity to PKC-delta inhibitor thus indicates clearly that early steps of retroviral replicative cycle are the major targets of PKCdelta inhibition.

To analyze further, we used Q-PCR and demonstrated that the inhibition of PKC-delta affected a step prior to the first strand transfer, but following initiation of RT. Thus, the major step altered by PKC-delta inhibition occurs early in RT. Several reports revealed that the actin cytoskeleton of the target cell plays an important role in the early steps of replication [52]. Indeed, the interaction between RT complexes and actin is not only essential for efficient RT, but also for the transport of preintegration complexes to the nucleus $[47,53,54]$. Indeed, pretreatment of cells with cytochalasin D (CCD), an inhibitor of actin polymerization, prevents the infection by HIV-1. Because effects of PKC-delta inhibitors on HIV-1 replication appeared to occur at a post entry step, we also analyzed the actin cytoskeleton. Indeed, the C2 domain of PKC-delta contains an actin-binding site, which could be involved in the redistribution of actin in neutrophils [42,43]. Accordingly, we demonstrated that rottlerin and siRNA against PKC-delta altered the actin cytoskeleton in macrophages, which is in agreement with previous studies on PKC-delta.

Correlated to the impairment of the actin cytoskeleton, we demonstrated that RT and p17 Ma proteins in the incoming RT complex, which are used frequently as markers to monitor the RT complex, did not co-fractionate with the cytoskeleton when PKC-delta was inhibited. Indeed, several additional lines of evidence demonstrated a link between actin cytoskeleton and HIV-1 replication. First, a block at the level of early RT was previously reported using cytochalasin D (CCD), an inhibitor of actin cytoskeleton polymerization $[47,55]$. Second, viral particlemediated induction of a signaling pathway via CXCR4 is required for infection of resting $\mathrm{T}$ cells [56-58]. In these cases, cofilin phosphorylates actin and participates in its redistribution, which overcomes the restriction related to cortical actin in resting $\mathrm{T}$ cells. Thirdly, Komano et al. demonstrated that inhibiting Arp 2/3, which is involved in actin polymerization, also restricts viral replication at an early stage in T cells [59]. Finally, Naghavi et al. implicated Moezin, which helps to tether cellular membranes to actin as being critical for early steps of viral replication [60]. Thus, our studies suggest that PKC-delta is a major signaling intermediary, which is activated by the virus to rearrange the actin network and thus facilitating early steps in the viral replicative cycle, particularly the RT step, in macrophages. Interestingly, recent studies have demonstrated the importance of a shallow endocytic pathway for HIV-1 entry and fusion [61]. Actin could thus play an important role in the completion of fusion after endocytosis. However, our VSV-G-pseudotyped vectors were not affected when PKC-delta was inhibited. Similar results were reported by Burkinskaya et al. who demonstrated that cytoskeletal impairment by CCD inhibits reverse transcription after entry of HIV-1, but not VSV-G pseudotyped vector. Thus, there is a difference between HIVand VSV-G-mediated entries that requires PKC-delta and actin cytoskeleton integrity. It is possible that $\mathrm{PKC}$-delta is critical only when fusion occurs independently of $\mathrm{pH}$, while it is not required when fusion occurs under low $\mathrm{pH}$ conditions in late endosomes. It could i) favor fusion and uncoating which involve both viral and cellular factors, ii) allow transport of RTCs to permissive compartments containing cellular factors required for RT, and iii) trigger activation of RTCs by interaction with actin. However the exact mechanism remains to be clarified.

Of note, viral nucleocapsid and integrase also interact with actin $[62,63]$. Both of these proteins and Vpr are part of the incoming reverse transcriptase complex.

Macrophages are a major target of HIV-1 infection, due to their high levels of expression of CCR5 and their persistence in infected individuals. Macrophages are residents of different organs and tissues, including the central nervous system, and thus can be found in different microenvironments in which regular therapies may be less effective than in circulating $\mathrm{CD} 4+\mathrm{T}$ cells. In these cells, pharmacokinetics and therapeutic efficiencies are understudied areas of research. Understanding better viral replication in macrophages could lead to the development of improved therapies in the future.

\section{Conclusions}

This work shows that PKC-delta is activated following interaction between $\mathrm{HIV}-1$ and human primary macrophages and plays a major role in viral replication. PKC-delta seems to play a role in early steps of the viral replicative cycle, allowing completion of reverse transcription. Our data suggest that this is due to a role of PKC-delta on the organization of proper actin cytoskeleton.

\section{Methods}

\section{Cell culture}

Peripheral blood mononuclear cells (PBMCs) were isolated from Buffy coats of healthy HIV-negative donors in a Ficoll density gradient (Pharmacia, Piscataway, NJ). PBMCs were then plated at a density of $10^{6}$ cells per well in 24-well Primaria (Becton Dickinson, Rutherford, NJ) tissue culture plates. Monocytes were isolated by adherence, after 45 minutes incubation in Iscove medium supplemented with human AB serum (10\%). Monocytes were then washed 3 times with HBSS and cultivated during 7 days in Iscove medium supplemented with 10\% Fetal Calf Serum (FCS), penicillin (100 units $/ \mathrm{ml}$ ) and streptomycin $(100 \mathrm{pg} / \mathrm{ml})$ at $37^{\circ} \mathrm{C}, 5 \% \mathrm{CO}_{2}$, in a humid atmosphere so that macrophages can differentiate. M-CSF 
(10 ng/ml, Roche) was added on the first day of culture. Macrophages are $94 \%$ pure as tested by FACS with antiCD14 antibody.

\section{Chemical inhibitors}

Ro31-8220, a PKC inhibitor, rottlerin, a PKC-delta inhibitor, Hispidin, a PKC-beta inhibitor, Go6976, inhibitor of calcium dependent PKC izozymes alpha and beta1 and of PKCmu and cytochalasin D, an inhibitor of actin polymerization, have been obtained from Calbiochem.

\section{SiRNAs}

Validated siRNA to human PKC-delta (Cat\# sc-36253) [45,64] and control siRNA (Cat\# sc-37007) were purchased from Santa Cruz Biotechnology (Santa Cruz, CA) and transfected in HeLa cells using siRNA transfection reagent from Santa Cruz Biotechnology (Cat\# sc-29528).

Accel siRNAs to human PKC-delta (Cat\# A-003524-160005) and control accel siRNA (Cat\# D-001910-01-05) were purchased from Thermo scientific and introduced in human primary macrophages without transfection reagent, by simple incubation for 2 days before infection with HIV-1 BaL. Targetting sequence for siRNA to PKCdelta is GUUCUGUGCAAAGACUU.

The following phosphorothioate oligonucleotides sense GCCCCACCATGGCGCCGTTC and antisense GAACGGCGCCATGGTGGGGC (target region on mRNA PKC -8 to +12) specific to PKC-delta were synthesized by Genset Oligos (Genset SA). Antisense oligonucleotides were previously assessed for their specificity [46] and used as previously described [46].

\section{Infection}

HeLa-R5/X4 (2.10 5 cells) were cultured in 12 well plates and transfected with siRNA control or siRNA PKC-delta (see above) using siRNA transfection reagent from Santa Cruz Biotechnology (Cat\# sc-29528) at 10 or $30 \mathrm{nM}$. After 48 h, cells were infected with HIV-1 BaL or HIV-1 VN44 in DMEM 2\% FCS and washed 2 times after 3 hours with DMEM. Cells were then cultivated in DMEM $10 \%$ FCS 1\% PS. After $24 \mathrm{~h}$, infection was scored via LTR-transactivation using X-gal coloration.

Macrophages $\left(5.10^{5}\right.$ cells) were cultured in 12 well plates and transfected with Accel siRNA control or Accel SiRNA PKC-delta at $10^{-6} \mathrm{M}$ (Thermofisher, see above). After $48 \mathrm{~h}$, cells were infected with HIV-1 BaL in DMEM 2\% FCS and washed 2 times after 3 hours with DMEM. Macrophages were then cultivated in DMEM $10 \%$ FCS 1\% PS. After 3 days, infection was assessed by detecting p24 in the supernatant using ELISA.

\section{Extraction of membrane and cytoplasmic proteins}

After treatment of macrophages with HIV-1 BaL, $1 \mathrm{ng}$ p24, macrophages $\left(5.10^{6}\right)$ were harvested at 30 minutes or $1 \mathrm{~h}$ and lysed at $4^{\circ} \mathrm{C}$ in $100 \mu \mathrm{l}$ of hypotonic buffer $\mathrm{A}$ (20 mM Tris $\mathrm{HCl}, 2 \mathrm{mM}$ EDTA, $1 \mathrm{mM}$ DTT, $10 \mu \mathrm{g} / \mathrm{ml}$ leupeptin, $1 \mathrm{mM}$ PMSF; $\mathrm{pH}$ 7,5) by repeated aspirations through a syringe fitted with a 21 Gauge needle. After the addition of $200 \mu \mathrm{l}$ of fresh buffer B (20 mM Tris $\mathrm{HCl}, 2 \mathrm{mM}$ EDTA, $1 \mathrm{mM}$ DTT, $10 \mu \mathrm{g} / \mathrm{ml}$ leupeptine, $1 \mathrm{mM}$ PMSF, $0.33 \mathrm{M}$ sucrose; $\mathrm{pH} 7.5$ ), the lysate was centrifuged at $100,000 \mathrm{~g}, 4^{\circ} \mathrm{C}$, for $40 \mathrm{~min}$. The supernatant, corresponding to the cytoplasmic fraction, was collected; proteins were quantified by the Bradford assay and stored at $-20^{\circ} \mathrm{C}$. The pellet, corresponding to the membrane fraction, was solubilised in $50 \mu \mathrm{l}$ of fresh B buffer containing $1 \%$ of Triton X-100, sonicated ( $1 \mathrm{~min}$, power 2.5), and the amount of proteins quantified and stored at $-20^{\circ} \mathrm{C}$.

\section{Extraction of total proteins}

After macrophage treatment with HIV-1 BaL, 1 ng p24, during 30 minutes or $1 \mathrm{~h}$, macrophages $\left(2.10^{6}\right)$ were harvested, centrifuged, and the pellet lysed in $200 \mu \mathrm{l}$ of PBS $1 \%$ NP-40. The amount of proteins was quantified by the Bradford assay and then proteins were stored at $-20^{\circ} \mathrm{C}$.

\section{Extraction of cytoplasmic, membrane and cytoskeleton fractions}

Macrophages $\left(5.10^{6}\right.$ cells) were lysed and cytoplasmic, membrane and cytoskeleton fractions obtained as previously described [47]. Anti-RT antibory is from abcam (ab63911) and anti-gagMA was obtained from the $\mathrm{NIH}$ reagents program.

\section{Western blotting}

Identical amounts of proteins $(10 \mu \mathrm{g})$ were separated on SDS-PAGE gel and then transferred to a nitrocellulose membrane. Immunoblotting was conducted by using either anti-PKC isozyme antibodies (anti-PKC-delta and anti PKC-beta II $_{\text {) }}$ at the 1:1000 dilution (Santa-Cruz biotechnology). Membranes were blocked in 5\% milk, Tris-buffered saline, $0.05 \%$ Tween 20 (TTBS) for $1 \mathrm{~h}$, washed 4 times with TTBS, and incubated with the primary antibody for $2 \mathrm{~h}$. Immuno-reactive bands were detected by $2 \mathrm{~h}$ incubation with secondary antibodies directed against rabbit immunoglobulins conjugated with peroxydase (1:1000) (DAKO A/S, Roskilde, Denmark). Bands were visualized on film after incubation of the membranes with a chemiluminescent substrate (Pierce, Rockford, IL).

\section{Lentiviral vectors}

$293 \mathrm{~T}$ cells $\left(2.5 .10^{6}\right)$ were cultured on a $150 \mathrm{~mm}$ Petri dish in DMEM 10\% FCS, penicillin $(100 \mathrm{U} / \mathrm{ml})$ and streptomycin $(10 \mathrm{pg} / \mathrm{ml})$, supplemented with L-glutamine ( $2 \mathrm{mM}$ ) for $24 \mathrm{~h}$. Cells were then cotransfected by the phosphate calcium method, with $30 \mu \mathrm{g}$ of gag-pol plasmid coding for capsid proteins and HIV-1 enzymes, $10 \mu \mathrm{g}$ of 
plasmid coding for the VSV-G envelope, and $40 \mu \mathrm{g}$ of lentiviral vector with GFP driven by CMV. The medium was changed $10 \mathrm{~h}$ after cotransfection. Supernatant was harvested $72 \mathrm{~h}$ after contransfection and centrifuged $15 \mathrm{~min}-$ utes at $2500 \mathrm{rpm}$. Supernatant was filtered through a $0.22 \mu \mathrm{m}$ filter and then ultracentrifuged 90 minutes at $50,000 \mathrm{~g}$. The pellet was finally resuspended in $100 \mu \mathrm{l} \mathrm{PBS}$.

\section{Transduction}

Macrophages, isolated as previously described in 24 well plates, were preincubated with or without rottlerin during 2 hours and then incubated $3 \mathrm{~h}$ at $37^{\circ} \mathrm{C}$ in $250 \mu \mathrm{l}$ of Iscove medium $2 \%$ FCS containing $50 \mu \mathrm{l}$ of VSV-G/GFP vector per well, in presence or absence of inhibitors. After 2 washes with PBS, cells were cultivated in Iscove medium, 10\% FCS. After 2 days, cells were visualized with a fluorescence microscope.

\section{Q-PCR}

$5 \times 10^{5}$ macrophages/well in a 24-well plate were incubated for $3 \mathrm{~h}$ at $37^{\circ} \mathrm{C}$ in the presence of HIV-1 BaL virus (1 ng p24/ml) pretreated with DNase I. Cells were then washed with HBSS and Iscove medium, 10\% FCS, 1\% penicillin/ streptomycin was added. Cells were then washed with HBSS at different times after infection. DNA was then extracted (Qiagen). For the detection of early (R-U5) and late (pol) reverse transcripts, DNA was amplified with the appropriate primers at $70^{\circ} \mathrm{C}$ in a LightCycler (Roche) with SYBR Green following the manufacturer's recommendations. Viral DNA was normalized by cellular genomic GAPDH. Primers sequence: Strong-stop: (1) agcctgggagctctctggcta and (2) ccagagtcacacaacagacgg; Late: (1) and (3) cgcttcagcaagccgagtcct, GAPDH gene: (4) : ctctgacttcaacagcgac and (5) : tctctcttcctcttgtgctc

\section{Actin cytoskeleton analysis}

Macrophages $\left(5.10^{5}\right.$ cells/well $)$ were resuspended and placed in wells containing a glass slide. After two cycles of adherence, macrophages were washed 2 times with PBS, and then fixed with PBS medium 3.7\% formaldehyde for 10 minutes at room temperature. After two more washes with PBS, macrophages were permeabilised by a $5 \mathrm{~min}$ incubation in the presence of $0.1 \%$ TRITON X-100. Two washes with PBS were performed, then cells were blocked with PBS 1\% BSA for $30 \mathrm{~min}$ to avoid non-specific labeling. Cells were then labeled with phalloidine-rhodamine (1U/well/200 $\mu \mathrm{l}$ of PBS 1\% BSA, Molecular Probes) for 20 minutes at room temperature. Macrophages were washed two more times with PBS and then mounted on cover slide using moviol and placed at $4^{\circ} \mathrm{C}$ until observation. Macrophages labeled with phalloidine-rhodamine were observed under a confocal microscope equipped with a $568 \mathrm{~nm}$ laser to excite the probe. 50 cells per slide were counted on at least 2 different slides per condition. Cells with clear pseudopodes were counted as positive while cells without pseudopodes or with small rare pseudopodes were negative. All results were normalized to control cells (100\%).

\section{Syncytia formation}

HeLa-R5/X4 (10000 cells) were cocultured with HeLagp120/gp41LAI or HeLa-gp-120/gp41ADA (10000 cells) in 96-well plates in the presence of various concentrations of each inhibitor. After $20 \mathrm{~h}$, syncytia were scored by contrast phase microscopy.

\section{Additional files}

Additional file 1: Figure S1. (A) Macrophages were incubated with different chemical inhibitors (left panel) or increasing doses of rottlerin for $72 \mathrm{~h}$ or DMSO as negative control. Cell viability was assessed by trypan blue staining. (B) Macrophages were incubated in the presence of sense or antisense oligonucleotides for 2 days and then infected with HIV-1 BaL (1ng p24) for $2 \mathrm{~h}$. Macrophages were then washed and supernant collected after 72 h. P24 was quantified by ELISA and percentage of inhibition measured. (C) Western blot showing expression of PKC-delta in cell extracts from macrophages incubated with sense or antisense oligonucleotides for $48 \mathrm{~h}$. As control, the effect of antisense PKC-delta was tested on the expression of PKC-alpha. In each case, antibodies specific to each PKC isoform were used in Western blot labeling.

Additinal file 2: Figure S2. HeLa CD4-CXCR4-CCR5 cells were left untreated or transfected with control siRNA (30nM) or siRNA to PKC-delta (10 or 30nM) and then infected with HIV-1 VN44 X4-tropic virus (1ng p24) for $3 \mathrm{~h}$ then washed. $48 \mathrm{~h}$ later, cells were incubated in the presence of X-gal and infection was assessed by counting beta-gal positive cells by microscopy.

Additional file 3: Figure S3. HeLa-R5/X4 cells with integrated LTR-beta-gal were preincubated or not with rottlerin $(5 \mu \mathrm{M})$ for 30 min and then left untreated or transduced using Gst-Tat $(5 \mu \mathrm{M})$. After 24 hours, beta-gal positive cells were scored using X-Gal by microscopy. LTR transactivation is relative and was set to $100 \%$ for Gst-Tat treated cells in absence of rottlerin.

Competing interests

The authors declare that they have no competing interests.

\section{Authors' contributions}

$X C$ and $E B$ conceived and designed the experiments and analyzed the data. $X C, O M$ and FG performed experiments. $X C$ and EB wrote the paper. All authors read and approved the final manuscript.

\section{Acknowledgements}

We would like to thank Dr. Fabian Gross for the gift of GFP lentiviral vectors, Dr. Marc Moreau for his help with confocal microscopy and Dr. Stéphane Emiliani for providing reagents. X.C. was supported in part by a grant from the National Institutes of Health, University of California San Francisco-Gladstone Institute of Virology \& Immunology Center for AIDS Research P30 AI27763 and the University of California, Berkeley Fogarty International AIDS Training Program (AITRP), and by a fellowship from Fondation de la Recherche Médicale. This work was supported by grants from SIDACTION, ANRS, ministère de la recherche et de la technologie and Université Paul SABATIER Toulouse III to EB and from the NIH RO1 Al49104 \& P50 GMO82250 to BMP.

\section{Author details}

'Université Paul Sabatier, EA 3038, 118 Route de Narbonne, Toulouse 31062 France. ${ }^{2}$ INSERM, U1043, CPTP, CHU purpan, BP3028, Toulouse, Cedex3 31024, France. ${ }^{3}$ CNRS, U5282, CPTP, CHU purpan, BP3028, Toulouse, Cedex3 31024, France. ${ }^{4}$ Department of Medicine, University of California, San Francisco CA94143, USA. ${ }^{5}$ CNRS UPR1142, IGH, Montpellier 34090, France. 
Received: 24 July 2011 Accepted: 15 March 2012

Published: 3 May 2012

\section{References}

1. Hirsch V, Sharkey M, Brown C, Brichacek B, Goldstein S, Wakefield J, Byrum R, Elkins W, Hahn B, Lifson J, Stevenson M: Vpx is required for dissemination and pathogenesis of SIV(SM) PBj: evidence of macrophage-dependent viral amplification. Nat Med 1998, 4:1401-1408.

2. Hu Q, Frank I, Williams V, Santos JJ, Watts P, Griffin GE, Moore JP, Pope M, Shattock RJ: Blockade of attachment and fusion receptors inhibits HIV-1 infection of human cervical tissue. J Exp Med 2004, 199:1065-1075.

3. Embretson J, Zupancic M, Ribas J, Burke A, Racz P, Tenner-Racz K, Haase A: Massive covert infection of helper $T$ lymphocytes and macrophages by HIV during the incubation period of AIDS. Nature 1993, 362:359-362.

4. Orenstein J, Fox C, Wahl S: Macrophages as a source of HIV during opportunistic infections. Science 1997, 276:1857-1861.

5. Shibata R, Igarashi T, Haigwood N, Buckler-White A, Ogert R, Ross W, Willey R, Cho MW, Martin MA: Neutralizing antibody directed against the HIV-1 envelope glycoprotein can completely block HIV-1/SIV chimeric virus infections of macaque monkeys. Nat Med 1999, 5:204-210.

6. Llewellyn N, Zioni R, Zhu H, Andrus T, Xu Y, Corey L, Zhu T: Continued evolution of HIV-1 circulating in blood monocytes with antiretroviral therapy: genetic analysis of HIV-1 in monocytes and CD4+ T cells of patients with discontinued therapy. J Leukoc Biol 2006, 80:1118-1126.

7. Briand G, Barbeau B, Tremblay M: Binding of HIV-1 to its receptor induces tyrosine phosphorylation of several CD4-associated proteins, including the phosphatidylinositol 3-kinase. Virology 1997, 228:171-179.

8. Davis C, Dikic I, Unutmaz D, Hill C, Arthos J, Siani M, Thompson D, Schlessinger J, Littman D: Signal transduction due to HIV-1 envelope interactions with chemokine receptors CXCR4 or CCR5. J Exp Med 1997, 186:1793-1798.

9. Harmon B, Ratner L: Induction of the G\{alpha\}q Signaling Cascade by the Human Immunodeficiency Virus Envelope Is Required for Virus Entry. J Virol Am Soc Microbiol 2008, 82:9191.

10. Popik W, Hesselgesser J, Pitha P: Binding of human immunodeficiency virus type 1 to CD4 and CXCR4 receptors differentially regulates expression of inflammatory genes and activates the MEK/ERK signaling pathway. J Virol 1998, 72:6406-6413.

11. Popik W, Alce TM, Au W-C: Human Immunodeficiency Virus Type 1 Uses Lipid Raft-Colocalized CD4 and Chemokine Receptors for Productive Entry into CD4+ T Cells. J Virol Am Soc Microbiol 2002, 76:4709-4722.

12. Veillette A, Bookman M, Horak E, Samelson L, Bolen J: Signal transduction through the CD4 receptor involves the activation of the internal membrane tyrosine-protein kinase p56lck. Nature 1989, 338:257-259.

13. Francois F, Klotman M: Phosphatidylinositol 3-kinase regulates human immunodeficiency virus type 1 replication following viral entry in primary CD4+ T lymphocytes and macrophages. J Virol 2003, 77:2539-2549.

14. Harmon B, Campbell N, Ratner L: Role of Abl kinase and the Wave2 signaling complex in HIV-1 entry at a post-hemifusion step. PLoS Pathog 2010, 6:e1000956.

15. Hassaine G, Courcoul M, Bessou G, Barthalay Y, Picard C, Olive D, Collette Y, Vigne R, Decroly E: The tyrosine kinase Hck is an inhibitor of HIV-1 replication counteracted by the viral vif protein. J Biol Chem 2001, 276:16885-16893.

16. Mettling C, Desmetz C, Fiser A-L, Réant B, Corbeau P, Lin Y-L: Gai proteindependant extracellular signal-regulated kinase- $1 / 2$ activation is required for HIV-1 reverse transcription. AIDS 2008, 22:1569-1576.

17. Schubert U, Schneider T, Henklein P, Hoffmann K, Berthold E, Hauser H, Pauli G, Porstmann T: Human-immunodeficiency-virus-type-1-encoded Vpu protein is phosphorylated by casein kinase II. Eur J Biochem 1992, 204:875-883.

18. Vita C: Rational engineering of a miniprotein that reproduces the core of the CD4 site interacting with HIV-1 envelope glycoprotein. Proc Natl Acad Sci 1999, 96:13091-13096.

19. Yang $X$, Gabuzda D: Mitogen-activated protein kinase phosphorylates and regulates the HIV-1 Vif protein. J Biol Chem 1998, 273:29879-29887.

20. Hamamoto Y, Matsuyama T, Yamamoto N, Kobayashi N: Augmentation of cytotoxic effect of tumor necrosis factor on human immunodeficiency virus-infected cells by staurosporine, a potent protein kinase $\mathrm{C}$ inhibitor. Cancer Res 1990, 50:5287-5290.

21. Meichle A, Schutze S, Hensel G, Brunsing D, Kronke M: Protein kinase Cindependent activation of nuclear factor kappa $B$ by tumor necrosis factor. J Biol Chem 1990, 265:8339-8343.
22. Wei P, Garber M, Fang S, Fischer W, Jones K: A novel CDK9-associated Ctype cyclin interacts directly with HIV-1 Tat and mediates its highaffinity, loop-specific binding to TAR RNA. Cell 1998, 92:451-462.

23. Griffin GE, Leung K, Folks TM, Kunkel S, Nabel GJ: Activation of HIV gene expression during monocyte differentiation by induction of NF-kB. Nature. Nature Publishing Group 1989, 339:70-73.

24. Lamph W, Wamsley P, Sassone-Corsi P, Verma I: Induction of protooncogene JUN/AP-1 by serum and TPA. Nature 1988, 334:629-631.

25. Siekevitz M, Josephs S, Dukovich M, Peffer N, Wong-Staal F, Greene W: Activation of the HIV-1 LTR by T cell mitogens and the trans-activator protein of HTLV-I. Science 1987, 238:1575-1578.

26. Burnette $B, Y u$ G, Felsted R: Phosphorylation of HIV-1 gag proteins by protein kinase C. J Biol Chem 1993, 268:8698-8703.

27. Baur AS, Sass G, Laffert B, Willbold D, Cheng-Mayer C, Peterlin BM: The $\mathrm{N}$-terminus of Nef from HIV-1/SIV associates with a protein complex containing Lck and a serine kinase. Immunity 1997, 6:283-291.

28. Guy B, Kieny M, Riviere Y, Le Peuch C, Dott K, Girard M, Montagnier L, Lecocq J: HIV F/3' orf encodes a phosphorylated GTP-binding protein resembling an oncogene product. Nature 1987, 330:266-269.

29. Guy B, Riviere Y, Dott K, Regnault A, Kieny M: Mutational analysis of the HIV nef protein. Virology 1990, 176:413-425.

30. Malim MH, Böhnlein S, Hauber J, Cullen BR: Functional dissection of the HIV-1 Rev trans-activator-Derivation of a trans-dominant repressor of Rev function. Cell 1989, 58:205-214.

31. Breitkreutz D, Braiman-Wiksman L, Daum N, Denning M, Tennenbaum T: Protein kinase C family: on the crossroads of cell signaling in skin and tumor epithelium. J Cancer Res Clin Oncol 2007, 133:793-808.

32. Ron $D$, Kazanietz $M:$ New insights into the regulation of protein kinase $C$ and novel phorbol ester receptors. FASEB J 1999, 13:1658-1676.

33. Sonza S, Maerz A, Deacon N, Meanger J, Mills J, Crowe S: Human immunodeficiency virus type 1 replication is blocked prior to reverse transcription and integration in freshly isolated peripheral blood monocytes. J Virol 1996, 70:3863-3869.

34. Sonza S, Mutimer H, Oelrichs R, Jardine D, Harvey K, Dunne A, Purcell D, Birch C, Crowe S: Monocytes harbour replication-competent, non-latent HIV-1 in patients on highly active antiretroviral therapy. AIDS 2001, 15:17-22.

35. Fantuzzi L, Conti L, Gauzzi M, Eid P, del Corno M, Varano B, Canini I, Belardelli F, Gessani S: Regulation of chemokine/cytokine network during in vitro differentiation and HIV-1 infection of human monocytes: possible importance in the pathogenesis of AIDS. J Leukoc Biol 2000, 68:391-399.

36. Weiden M, Tanaka N, Qiao Y, Zhao B, Honda Y, Nakata K, Canova A, Levy D, Rom W, Pine R: Differentiation of monocytes to macrophages switches the Mycobacterium tuberculosis effect on HIV-1 replication from stimulation to inhibition: modulation of interferon response and CCAAT/enhancer binding protein beta expression. J Immunol 2000, 165:2028-2039.

37. Junttila I, Bourette R, Rohrschneider L, Silvennoinen O: M-CSF induced differentiation of myeloid precursor cells involves activation of PKC-delta and expression of Pkare. J Leukoc Biol 2003, 73:281-288.

38. Kang H, Park E, Kim K, Park J, Choi J, Shin H, Jun C, Kang S, Kim S: Receptor activator of nuclear factor-kappaB is induced by a rottlerin-sensitive and p38 MAP kinase-dependent pathway during monocyte differentiation. Mol Cells 2004, 17:438-445.

39. Mischak H, Pierce J, Goodnight J, Kazanietz M, Blumberg P, Mushinski J: Phorbol ester-induced myeloid differentiation is mediated by protein kinase C-alpha and -delta and not by protein kinase C-beta II, -epsilon, -zeta, and -eta. J Biol Chem 1993, 268:20110-20115.

40. Biswas D, Ahlers C, Dezube B, Pardee A: Pentoxifylline and other protein kinase $C$ inhibitors down-regulate HIV-LTR NF-kappa B induced gene expression. Mol Med 1994, 1:31-43.

41. Owen $P$, Johnson $G$, Lord J: Protein kinase C-delta associates with vimentin intermediate filaments in differentiated HL60 cells. Exp Cell Res 1996, 225:366-373.

42. Lopez-Lluch G, Bird M, Canas B, Godovac-Zimmerman J, Ridley A, Segal A, Dekker L: Protein kinase C-delta C2-like domain is a binding site for actin and enables actin redistribution in neutrophils. Biochem J 2001, 357:39-47.

43. Smallwood N, Hausman B, Wang X, Liedtke C: Involvement of NH2 terminus of PKC-delta in binding to F-actin during activation of Calu-3 airway epithelial NKCC1. Am J Physiol Cell Physiol 2005, 288:C906-C912.

44. Lopez-Huertas MR, Mateos E, Diaz-Gil G, Gomez-Esquer F, Sanchez Del Cojo M, Alcami J, Coiras M: Protein kinase C (PKC) theta (\{theta\}) is a specific target 
for the inhibition of the human immunodeficiency virus type 1 (HIV-1) replication in CD4+ T lymphocytes. J Biol Chem 2011, 286:27363-27377.

45. Lemjabbar-Alaoui H, Sidhu SS, Mengistab A, Gallup M, Basbaum C: TACE/ ADAM-17 phosphorylation by PKC-epsilon mediates premalignant changes in tobacco smoke-exposed lung cells. PLoS One 2011, 6:e17489.

46. Bennasser Y, Bahraoui E: HIV-1 Tat protein induces interleukin-10 in human peripheral blood monocytes: involvement of protein kinase C-betall and -delta. FASEB J 2002, 16:546-554.

47. Bukrinskaya A: Establishment of a Functional Human Immunodeficiency Virus Type 1(HIV-1) Reverse Transcription Complex Involves the Cytoskeleton. J Exper Med 1998, 188:2113-2125.

48. Mzoughi O, Gaston F, Granados GC, Lakhdar-Ghazal F, Giralt E, Bahraoui E: Fusion intermediates of HIV-1 gp41 as targets for antibody production: design, synthesis, and HR1-HR2 complex purification and characterization of generated antibodies. ChemMedChem 2010, 5:1907-1918.

49. Campbell E, Nunez R, Hope T: Disruption of the actin cytoskeleton can complement the ability of Nef to enhance human immunodeficiency virus type 1 infectivity. J Virol 2004, 78:5745-5755.

50. Warrilow D, Gardner J, Darnell GA, Suhrbier A, Harrich D. HIV Type 1 Inhibition by Protein Kinase C Modulatory Compounds. [http://dx.doi.org/ 10.1089/aid.2006.22.854]. Mary Ann Liebert, Inc. 2 Madison Avenue Larchmont, NY 10538 USA;2006 22:854-864.

51. Williams S, Chen L, Kwon H, Fenard D, Bisgrove D, Verdin E, Greene W: Prostratin antagonizes HIV latency by activating NF-kappaB. J Biol Chem 2004, 279:42008-42017.

52. Wu Y, Yoder A: Chemokine co-receptor signaling in HIV-1 infection and pathogenesis. PLOS Pathog 2009, 5:e1000520.

53. Arhel N, Genovesio A, Kim K-A, Miko S, Perret E, Olivo-Marin J-C, Shorte S, Charneau P: Quantitative four-dimensional tracking of cytoplasmic and nuclear HIV-1 complexes. Nat Methods 2006, 3:817-824.

54. Michael H, Gramatikoff K, Georgiev O, Chaponnier C, Schaffner W, Hübscher $\mathrm{U}$ : The large subunit of $\mathrm{HIV}-1$ reverse transcriptase interacts with $\beta$-actin. Nucleic Acids Res 1995, 23:736-741.

55. lyengar S, Hildreth J, Schwartz D: Actin-dependent receptor colocalization required for human immunodeficiency virus entry into host cells. J Virol $1998,72: 5251-5255$.

56. Cameron PU, Saleh S, Sallmann G, Solomon A, Wightman F, Evans VA, Boucher G, Haddad EK, Sekaly R-P, Harman AN, Anderson JL, Jones KL, Mak J, Cunningham AL, Jaworowski A, Lewin SR: Establishment of HIV-1 latency in resting CD4+ T cells depends on chemokine-induced changes in the actin cytoskeleton. Proc Natl Acad Sci USA 2010, 107:16934-16939.

57. Vorster PJ, Guo J, Yoder A, Wang W, Zheng Y, Xu X, Yu D, Spear M, Wu Y: LIM Kinase 1 Modulates Cortical Actin and CXCR4 Cycling and Is Activated by HIV-1 to Initiate Viral Infection. J Biol Chem 2011, 286:12554-12564.

58. Yoder A, Yu D, Dong L, Iyer SR, Xu X, Kelly J, Liu J, Wang W, Vorster PJ, Agulto L, Stephany DA, Cooper JN, Marsh JW, WU Y: HIV envelope-CXCR4 signaling activates cofilin to overcome cortical actin restriction in resting CD4 T cells. Cell 2008, 134:782-792.

59. Komano J, Miyauchi K, Matsuda Z, Yamamoto N: Inhibiting the Arp2/3 complex limits infection of both intracellular mature vaccinia virus and primate lentiviruses. Mol Biol Cell 2004, 15:5197-5207.

60. Naghavi MH, Valente S, Hatziioannou T, de Los Santos K, Wen Y, Mott C, Gundersen GG, Goff SP: Moesin regulates stable microtubule formation and limits retroviral infection in cultured cells. EMBO J 2007, 26:41-52.

61. Miyauchi K, Kim Y, Latinovic O, Morozov V, Melikyan GB: HIV enters cells via endocytosis and dynamin-dependent fusion with endosomes. Cell 2009, 137:433-444.

62. Turlure F, Devroe E, Silver PA, Engelman A: Human cell proteins and human immunodeficiency virus DNA integration. Front Biosci 2004, 9:3187-3208.

63. Wilk T, Gowen B, Fuller SD: Actin Associates with the Nucleocapsid Domain of the Human Immunodeficiency Virus Gag Polyprotein. I Virol Am Soc Microbiol 1999, 73.

64. Torgersen ML, Wälchli S, Grimmer S, Skånland SS, Sandvig K: Protein kinase Cdelta is activated by Shiga toxin and regulates its transport. J Biol Chem 2007, 282:16317-16328.

doi:10.1186/1742-4690-9-37

Cite this article as: Contreras et al:: Protein kinase C-delta regulates HIV1 replication at an early post-entry step in macrophages. Retrovirology 2012 9:37.

\section{Submit your next manuscript to BioMed Central and take full advantage of:}

- Convenient online submission

- Thorough peer review

- No space constraints or color figure charges

- Immediate publication on acceptance

- Inclusion in PubMed, CAS, Scopus and Google Scholar

- Research which is freely available for redistribution 